\title{
Pengembangan perangkat pembelajaran inkuiri berbasis tambak air tawar untuk meningkatkan pemahaman konsep, keterampilan proses sains dan sikap peduli lingkungan siswa
}

\author{
Vilda Rima Aulia Zahroh, Ibrohim*, Sueb \\ Universitas Negeri Malang, Jl. Semarang No. 5 Malang, Jawa Timur, Indonesia \\ *Penulis korespondensi, Surel: ibrohim.fmipa@um.ac.id
}

Paper received: 02-01-2021; revised: 15-01-2021; accepted: 30-01-2021

\begin{abstract}
The aim of this research is to produce inquiry learning instrument based on freshwater fishpond that meet valid, practical, and effective criteria. This method of research and development uses 4D Thiagarajan et al. (1974) development model but it is restricted up to Disseminate in the summative evaluation substage. Analysis result validation of learning instrument is 94.26 percent, it means that comply criteria is very valid. The result of practicality from lesson plan, student worksheet and hand-out are 92.25 percent, 89.11 percent and 85.78 percent it means that comply criteria is very practical. The effectiveness indicates that there is difference and increase the value of concept comprehension, science process skills and student environmental awareness attitude posttest and student that cooperative learning instrument.
\end{abstract}

Keywords: inquiry learning instrument based on freshwater fishpond; concept comprehension; science process skills and student environmental; awareness attitude

\begin{abstract}
Abstrak
Penelitian ini bertujuan untuk menghasilkan perangkat pembelajaran yang memenuhi kriteria valid, praktis dan efektif. Penelitian ini menggunakan model pengembangan 4D oleh Thiagarajan et al. (1974) namun dibatasi sampai tahap Disseminate sub tahap summative evaluation. Hasil uji kevalidan perangkat pembelajaran sebesar 94,26 persen yang menunjukkan kriteria sangat valid. Hasil uji kepraktisan dari keterlaksanaan perangkat pembelajaran, LKS dan hand-out sebesar 92,25 persen, 89,11 persen dan 85,78 persen yang memenuhi kriteria sangat praktis. Uji keefektifan menunjukkan bahwa terdapat perbedaan dan peningkatan rerata skor posstest pemahaman konsep, keterampilan proses sains dan sikap peduli lingkungan siswa pada kelas yang menggunakan perangkat pembelajaran inkuiri berbasis tambak air tawar dibanding dengan siswa yang menggunakan perangkat pembelajaran model kooperatif.
\end{abstract}

Kata kunci: perangkat pembelajaran inkuiri berbasis tambak air tawar; pemahaman konsep; keterampilan proses sains; sikap peduli lingkungan

\section{Pendahuluan}

Pembelajaran yang berlangsung di sekolah harus menjadikan siswa aktif dan mampu memberikan ruang yang cukup bagi prakarsa, kreativitas, kemandirian sesuai dengan bakat, minat dan perkembangan fisik serta psikologis sesuai dengan Kurikulum 2013 (Permendikbud No. 22, 2016). Kurikulum 2013 dirancang menggunakan model kurikulum berbasis kompetensi yang ditandai oleh pengembangan kompetensi berupa sikap, pengetahuan, keterampilan berpikir dan keterampilan psikomotorik yang dikemas dalam berbagai mata pelajaran (Kemendikbud, 2012). Permendikbud No. 22 (2016) menyarankan untuk memperkuat pendekatan ilmiah dan tematik sesuai dengan Kurikulum 2013 maka perlu diterapkan belajar berbasis penelitian (inquiry).

Pembelajaran inkuiri merupakan salah satu komponen pembelajaran yang sangat penting dan sesuai untuk digunakan dalam reformasi pembelajaran sains masa kini 
(Wenning, 2011). Selain itu untuk menghasilkan pembelajaran yang efektif guna menyiapkan siswa dengan pengetahuan, keterampilan dan nilai lingkungan perlu diciptakan lingkungan belajar yang mendukung dan kontekstual (Burns, 2011). Penelitian oleh Ibrohim (2015) menyimpulkan bahwa pembelajaran yang bermakna dapat dilakukan melalui pembelajaran yang memanfaatkan sumber belajar dari konteks lingkungan yang erat dengan kehidupan sehari-hari siswa. Salah satu potensi lokal yang ditemukan di Kabupaten Lamongan ialah tambak air tawar.

Tambak merupakan salah satu potensi daerah Kabupaten Lamongan yang banyak ditemukan dan sebagai sumberdaya perikanan budidaya, bersumber dari LPJ Kepala Daerah Tahun 2015 Gubernur Jawa Timur menetapkan Kabupaten Lamongan sebagai kawasan minapolitan dimana Kecamatan Glagah sebagai pusat pengembangan minapolitan budidaya. Sanjaya (2015) menyatakan bahwa sumber belajar dari lingkungan merupakan sumber belajar yang sangat sesuai dengan tuntutan kurikulum.

Sumber belajar dari lingkungan ternyata belum sepenuhnya diterapkan di MTs N 2 Lamongan. Berdasarkan hasil wawancara kepada Guru dan Siswa dapat disimpulkan bahwa nilai ulangan harian masih banyak dibawah KKM yakni 75. Selain itu siswa masih kesulitan untuk menyampaikan hasil observasi sehingga keterampilan proses sains belum dapat dikembangkan. Kurangnya kepedulian siswa terhadap tambak sebagai potensi daerahnya menjadikan siswa mengenal tambak sebagai sebaatas tempat mata pencaharian bagi petani ikan dan habitat bagi ikan.

Berdasarkan uraian di atas maka diperlukan persiapan mengajar yang baik agar berkualitas dan bermakna (Kunandar, 2013). Persiapan pembelajaran yang dibutuhkan berupa perangkat pembelajaran model inkuiri dengan sumber belajar tambak air tawar untuk meningkatkan pemahaman konsep, keterampilan proses sains dan sikap peduli lingkungan siswa. Tujuan penelitian ini ialah menghasilkan produk berupa perangkat pembelajaran yang memenuhi syarat valid, praktis dan efektif.

\section{Metode}

Penelitian ini menggunakan penelitian dan pengembangan dengan model pengembangan 4D oleh Thiagarajan et al. (1974) namun pada penelitian ini dibatasi sampai tahap disseminate sub tahap summative evaluation karena keterbatasan waktu. Data penelitian berupa data kuantitatif dan kualitatif. Data kuantitatif berupa skor hasil validasi, hasil angket respons siswa terhadap keterbacaan, hasil tes siswa dan keterlaksanaan pembelajaran sedangkan data kualitatif berupa komentar/ saran yang diberikan oleh para validator. Pengumpulan data dilakukan dengan cara penerapan perangkat pembelajaran yang dikembangkan kepada siswa untuk mengetahui keefektifannya. Instrumen yang digunakan berupa pedoman wawancara, angket kebutuhan guru, lembar validasi, angket keterbacaan, lembar keterlaksanaan pembelajaran, lembar tes dan angket. Analisis data dilakukan pada tahap develop dan tahap disseminate sub tahap summative evaluation. Data dianalisis menggunakan teknik perhitungan persentase yang disesuaikan dengan tabel kriteria, gain score dan uji statistika Quade's rank analysis of covariance. 


\section{Hasil dan Pembahasan}

\subsection{Hasil Validasi Ahli}

Hasil validasi ahli digunakan untuk memperoleh nilai dan saran sehingga diketahui layak tidaknya produk yang dikembangkan.Validasi dilakukan oleh ahli desain perangkat pembelajaran, ahli materi, pakar evaluasi dan praktisi lapangan. Hasil validasi ahli disajikan pada Tabel 1.

\section{Tabel 1. Hasil Validasi dari Keempat Ahli}

\begin{tabular}{llll}
\hline No. & Perangkat Pembelajaran & Rerata Skor (\%) & Kategori \\
\hline 1. & Silabus & 98,83 & Sangat Valid \\
2. & RPP & 96,53 & Sangat Valid \\
3. & Hand-out & & \\
& Hand-out (Ahli Desain Perangkat Pembelajaran) & 99,48 & Sangat Valid \\
& Hand-out (Ahli Materi) & 86,96 & Sangat Valid \\
4. & LKS & 97,08 & Sangat Valid \\
5. & Instrumen Penilaian & 86,65 & Sangat Valid \\
\hline
\end{tabular}

Berdasarkan Tabel 1 diketahui bahwa hasil validasi perangkat pembelajaram memiliki kriteria sangat valid dengan rerata skor yang diperoleh sebesar 94,26\%. Kriteria tersebut mengindikasikan bahwa perangkat pembelajaran yang dikembangkan dapat diterapkan kepada siswa.

\subsection{Hasil Uji Keterbacaan}

Uji keterbacaan dilakukan untuk memperoleh komentar dan saran terhadap LKS dan hand-out dari siswa yang telah menempuh mata pelajaran IPA materi ekosistem yakni siswa kelas VIII dalam penelitian ini dilakukan uji keterbacaan kepada siswa kelas VIII F MTs N 2 Lamongan. Uji keterbacaan tersebut menjadi acuan dalam merevisi produk sebelum diterapkan kepada siswa. Hasil uji keterbacaan LKS dan hand-out berturut-turut dapat dilihat pada Tabel 2 dan Tabel 3.

Tabel 2. Rangkuman Hasil Uji Keterbacaan LKS

\begin{tabular}{clll}
\hline No & Sub Indikator Penilaian & Rerata Tingkat Keterbacaan (\%) & Keterangan \\
\hline 1. & Komponen dalam LKS & 86,25 & Sangat Layak \\
2. & Kebahasaan & 87,71 & Sangat Layak \\
3. & Penyajian & 83,75 & Layak \\
4. & Tampilan & 95,94 & Sangat Layak \\
5. & Manfaat & 91,88 & Sangat Layak \\
\hline & Rerata total & 89,11 & Sangat Layak \\
\hline
\end{tabular}

Tabel 3. Rangkuman Hasil Uji Keterbacaan Hand-out

\begin{tabular}{llll}
\hline No & Sub Indikator Penilaian & Rerata Tingkat Keterbacaan (\%) & Keterangan \\
\hline 1. & Komponen dalam hand-out & 81,96 & Layak \\
2. & Kebahasaan & 87,71 & Sangat Layak \\
3. & Penyajian & 85,50 & Sangat Layak \\
4. & Tampilan & 93,75 & Sangat Layak
\end{tabular}




\begin{tabular}{|c|c|c|c|}
\hline 5. & Manfaat & 80,00 & Layak \\
\hline & Rerata total & 85,78 & Sangat Layak \\
\hline
\end{tabular}

Berdasarkan Tabel 3 dan Tabel 4 di atas mengenai rerata tingkat keterbacaan LKS dan hand-out berturut sebesar $89,11 \%$ dan $85,78 \%$. Persentase tersebut menunjukkan bahwa LKS dan hand-out yang dikembangkan memenuhi kriteria sangat layak untuk diterapkan kepada siswa kelas VII.

\section{Hasil Uji Kepraktisan}

Hasil uji kepraktisan didapatkan dari keterlaksanaan pembelajaran yang menggunakan sintkas inkuiri terbimbing (Llewelyn, 2013). Kemunculan sintaks inkuiri terbimbing tersebut disesuaikan dengan indikator pada lembar observasi yang diamati oleh satu orang observer yakni guru mata pelajaran IPA. Berikut Tabel 4 hasil keterlaksanaan pembelajaran.

Tabel 4. Rerata Skor Keterlaksanaan Pembelajaran

\begin{tabular}{lllll}
\hline No. & Tahapan & $\begin{array}{l}\text { Skor } \\
\text { Total }\end{array}$ & $\begin{array}{l}\text { Skor } \\
\text { Maksimal }\end{array}$ & $\begin{array}{l}\text { Rerata } \\
\text { Keterlaksanaan (\%) }\end{array}$ \\
\hline 1. & Pra Pembelajaran & 12 & 12 & 100,00 \\
2. & Kegiatan Awal & 12 & 12 & 100,00 \\
3. & Kegiatan Inti & 61 & 72 & 84,72 \\
4. & Kegiatan Penutup & 15 & 16 & 93,75 \\
5. & Pasca Pembelajaran & 3 & 4 & 75,00 \\
6. & Komentar Umum & 4 & 4 & 100,00 \\
\hline & Rerata Keterlaksanaan & & & 92,25 \\
\hline
\end{tabular}

Berdasarkan Tabel 4 keterlaksanaan pembelajaran menunjukkan rerata sebesar $92,25 \%$ yakni pembelajaran yang berlangsung sesuai dengan sintaks inkuiri terbimbing. Hal tersebut menunjukkan bahwa perangkat pembelajaran yang dikembangkan memenuhi kriteria sangat praktis jika dterapkan lebih lanjut.

\section{Hasil Uji Keefektifan}

Analisis uji kefektifan dilakukan menggunakan uji statistik Quade's rank analysis of covariance karena data yang didapat tidak normal dan tidak homogen. Produk pengembangan diterapkan kepada siswa kelas VII A MTs N 2 Lamongan sebanyak 26 siswa dan dibandingakn dengan kelas VII G sebanyak 29 siswa yang menggunakan perangkat pyyembelajaran rancangan guru. Berikut hasil uji Quade's rank analysis of covariance pemahaman konsep keterampilan proses sains dan sikap peduli lingkungan siswa berturutturut pada Tabel 5, Tabel 6 dan Tabel 7 serta gain score padaTabel 8.

Tabel 5. Hasil Uji Quade's rank analysis of covariance Pemahaman Konsep

\begin{tabular}{llllll}
\hline & Sum of Squares & Df & Mean Square & F & Sig. \\
\hline Between Groups & 1148,278 & 1 & 1148,278 & 12,431 &, 001 \\
Within Groups & 4895,572 & 53 & 92,369 & & \\
Total & 6043,850 & 54 & & & \\
\hline
\end{tabular}


Tabel 6. Hasil Uji Quade's rank analysis of covariance Keterampilan Proses Sains

\begin{tabular}{lllllc}
\hline & Sum of Squares & Df & Mean Square & F & Sig. \\
\hline Between Groups & 226,086 & 1 & 226,086 & $24,821,000$ \\
Within Groups & 482,756 & 53 & 9,109 & & \\
Total & 708,842 & 54 & & & \\
\hline
\end{tabular}

Tabel 7. Hasil Uji Quade's rank analysis of covariance Sikap Peduli Lingkungan Siswa

\begin{tabular}{llllll}
\hline & Sum of Squares & df & Mean Square & F & Sig. \\
\hline Between Groups & 7221,520 & 1 & 7221,520 & $58,254,000$ \\
Within Groups & 6570,247 & 53 & 123,967 & & \\
Total & 13791,767 & 54 & & & \\
\hline
\end{tabular}

Tabel 8. Rangkuman gain score Pemahaman Konsep, Keterampilan Proses Sains dan Sikap Peduli Lingkungan Siswa

\begin{tabular}{lll}
\hline & Gain Score & \\
\cline { 2 - 3 } & Model Inkuiri Terbimbing & Model Kooperatif \\
\hline Pemahaman Konsep & 0,43 & 0,18 \\
Keterampilan Proses Sains & 0,35 & 0,28 \\
Sikap Peduli Lingkungan & 0,43 & 0,35 \\
\hline
\end{tabular}

Berdasarkan Tabel 5, Tabel 6, dan Tabel 7 diketahui nilai p pemahaman konsep, keterampilan proses sains dan sikap peduli lingkungan sebesar 0,001; 0,000; dan 0,000 yang menunjukkan bahwa $\mathrm{p}<\alpha(\alpha=0,05)$ artinya terdapat perbedaan pemahaman konsep, keterampilan proses sains dan sikap peduli lingkungan antara siswa yang dibelajarkan dengan perangkat pembelajaran inkuiri berbasis tambak dengan siswa yang dibelajarkan dengan perangkat pembelajaran model kooperatif. Selain itu Tabel 8 menunjukkan bahwa terdapat peningkatan pemahaman konsep, keterampilan proses sains dan sikap peduli lingkungan siswa setelah dibelajarkan dengan perangkat yang dikembangkan

Proses belajar mengajar yang berkualitas dan bermakna harus didahului dengan persiapan mengajar yang baik, tanpa persiapan mengajar yang baik maka sulit menghasilkan pembelajaran yang berkualitas dan bermakna (Kunandar, 2013). Perencanaan pembelajaran menurut Permendikbud No.22 (2016) terdiri dari silabus, RPP, bahan ajar serta perangkat penilaian yang dikembangkan oleh pemerintah, pemerintah daerah, dan satuan pendidikan disesuaikan dengan kewenangan masing-masing. Pengembangan perangkat pembelajaran pada penelitian ini disesuaikan dengan potensi lokal yang ada di daerah Lamongan yakni tambak air tawar sebagai sumber belajar yang jarang digunakan.

Perangkat pembelajaran yang dikembangkan diuji kevalidan dan keterbacaannya sebelum diterapkan kepada siswa langsung. Berdasarkan hasil validasi silabus, RPP, LKS, hand-out dan instrumen penilaian didapat rerata skor berturut-turut sebesar 98,83\%, 96,53\%, 97,08\%, 93,22\% dan 86,65\% yang menunjukkan bahwa perangkat pembelajaran yang dikembangkan memenuhi kriteria sangat valid. Hasil uji keterbacaan LKS dan hand-out sebesar 89,11\% dan 85,78\% yang menunjukkan bahwa sangat layak untuk dikembangkan. 
Silabus, RPP, LKS dan hand-out dikembangkan menggunakan model pembelajaran inkuiri terbimbing oleh Llewelyn (2013). Menurut Corlu \& Corlu (2012) pembelajaran inkuiri memungkinkan siswa terlibat aktif dalam kegiatan pembelajaran dengan melakukan penelitian dan investigasi dalam rangka membangun pengetahuannya sendiri seperti yang dilakukan oleh ilmuwan. Komponen silabus dan RPP dirancang sesuai dengan Permendikbud No. 22 (2016) tentang standar proses. Pembelajaran dilaksanakan sebanyak 3 kali pertemuan dengan alokasi waktu 5×40 menit (dua pertemuan di kelas dan satu pertemuan di tambak).

LKS dikembangkan dengan menggunakan sumber belajar tambak air tawar yang berada di belakang sekolah. Menurut Prastowo (2015) pengembangan LKS perlu dilakukan sendiri oleh guru agar LKS yang dihasilkan lebih kontekstual dengan situasi dan kondisi sekolah ataupun lingkungan sosial budaya siswa. LKS dikembangkan memuat 2 kegiatan yakni merancang pengamatan dan melaksanakan pengamatan yang dilakukan oleh siswa. Hal tersebut sesuai dengan Trianto (2012) yang menyatakan bahwa LKS memuat sekumpulan kegiatan mendasar yang harus dilakukan oleh siswa untuk memaksimalkan pemahaman dalam upaya pembentukan kemampuan dasar sesuai indikator pencapaian hasil belajar yang ditempuh.

Hand-out dikembangkan berisi uraian materi yang berkaitan dengan materi ekosistem yang ada di tambak air tawar. Materi hand-out diambil dari beberapa literatur yang memiliki relevansi dengan materi yang diajarkan, KD, materi pokok yang harus dikuasai oleh siswa (Depdiknas, 2008). Selain itu materi pembelajaran yang terdapat pada hand-out juga dikaitkan dengan kondisi yang ada disekitar siswa yakni tambak air tawar. Hal ini dimaksudkan agar hand-out yang dihasilkan lebih kontekstual dan mudah dipahami siswa karena berdasarkan fakta atau fenomena yang ada di lingkungan siswa (Ibrohim, 2015).

Uji keefektifan menujukkan bahwa perangkat pembelajaran efektif meningkatkan pemahaman konsep, keterampilan proses sains dan sikap peduli lingkungan siswa yang dibelajarkan dengan perangkat pembelajaran inkuiri berbasis tambak air tawar dibandingkan dengan siswa yang dibelajarkan dengan perangkat pembelajaran model kooperatif. Penelitian yang dilakukan oleh Salim \& Tiawa (2015), Nurhadi et al., (2016), Sen \& Vekli (2016), Mardikaningtyas et al., (2016) dan Febriana et al., (2016) menyimpulkan bahwa pembelajaran menggunakan model inkuri mampu menunjang pemahaman konsep, keterampilan proses sains, dan sikap peduli lingkungan siswa. Keterlaksanaan pembelajaran menunjukkan rerata sebesar 92,25\% yakni pembelajaran yang berlangsung sesuai dengan sintaks inkuiri terbimbing dan perangkat pembelajaran yang dikembangkan memenuhi kriteria sangat praktis jika dterapkan lebih lanjut.

\section{Simpulan}

Berdasarkan hasil penelitian pengembangan menunjukkan bahwa perangkat pembelajaran inkuiri berbasis tambak air tawar memenuhi kriteria layak dan praktis serta efektif dalam meningkatkan pemahaman konsep, keterampilan proses sains dan sikap peduli lingkungan siswa. Saran yang diberikan ialah perangkat pembelajaran perlu disebarkan melalui forum musyawarah guru agar dapat dimanfaatkan lebih lanjut dan diharapkan setiap guru mampu mengembangkan pembelajaran dengan memanfaatkan konteks lingkungan. 


\section{Daftar Rujukan}

Burns, H. (2011). Teaching for transformation:(Re) Designing sustainability courses based on ecological principles. Journal of Sustainability Education.

Çorlu, M. A., \& Çorlu, M. S. (2012). Scientific Inquiry Based Professional Development Models in Teacher Education. Educational Sciences: Theory and Practice, 12(1), 514-521.

Febriana, I., \& Mahanal, S. (2016). Potensi Pembelajaran Inkuiri dalam Menumbuhkan Sikap Siswa terhadap Lingkungan. Prosiding. Semnas Pend IPA Pascasarjana UM, 1.

Ibrohim, I. (2015, September). Pengembangan pembelajaran ipa/biologi berbasis discovery/inquiry dan potensi lokal untuk meningkatkan keterampilan dan sikap ilmiah serta menumbuhkan jiwa kewirausahaan. In Seminar Nasional Sains dan Entrepreneurship II.

Kebudayaan, K. P. D. (2012). Dokumen kurikulum 2013. Jakarta: Kemendikbud.

Kunandar, K. (2013). Penilaian autentik (Penilaian hasil belajar peserta didik berdasarkan Kurikulum 2013). Jakarta: Rajawali Pers.

Lllewelyn, D. (2013). Teaching High School Science Through Inquiry and Argumantation.

Mardikaningtyas, D. A., Ibrohim, I., \& Suarsini, E. (2016). Pengembangan Pembelajaran Pencemaran Lingkungan Berbasis Penelitian Fitoremediasi untuk Menunjang Keterampilan Ilmiah, Sikap Peduli Lingkungan dan Motivasi Mahasiswa pada Matakuliah Dasar-Dasar Ilmu Lingkungan.Jurnal Pendidikan: Teori, Penelitian, dan Pengembangan, 1(3), 499-506.

Nasional, D. P. (2008). Panduan pengembangan bahan ajar.

Nurhadi. Lukman. Abas, R., Erni. Yuliana \& Hamrina. (2014). Implementation of Inquiry Based Learning to Improve Understanding the Concept Electric Dynamic and Thinking Skills (an empirical study in class IX Junior High School Students State 4 Kendari). International Journal of Science and Research (IJSR) 5 (3), 471-479. Dari https://www.ijsr.net/archive/v5i3/NOV161532.pdf

Pendidikan, K., \& Indonesia, K. R. (2016). Permendikbud Nomor 22 Tahun 2016 Tentang Standar Proses Pendidikan Dan Menengah. Jakarta: Kemendikbud.

Prastowo, A. (2011). Panduan kreatif membuat bahan ajar inovatif.

Salim, K., \& Tiawa, D. H. (2015). Implementation of Structured Inquiry Based Model Learning toward Students' Understanding of Geometry. International journal of research in education and science, 1(1), 75-83.

Sanjaya, W. (2015). Perencanaan dan desain sistem pembelajaran. Kencana.

Sen, C., \& Sezen Vekli, G. (2016). The Impact of Inquiry Based Instruction on Science Process Skills and SelfEfficacy Perceptions of Pre-Service Science Teachers at a University Level Biology Laboratory. Universal Journal of Educational Research, 4(3), 603-612.

Thiagarajan, S. (1974). Instructional development for training teachers of exceptional children: A sourcebook.

Trianto. (2008). Mendesain Pembelajaran Kontekstual (Contextual Teaching and Learning) di Kelas. Jakarta: Cerdas Pustaka Publisher.

Wenning, C. J. (2011). Experimental inquiry in introductory physics courses. Journal of Physics Teacher Education Online, 6(2), 2-8. 